Article

\title{
Scientific Knowledge Integration and the Implementation of the SDGs: Comparing Strategies of Sustainability Networks
}

\author{
Ulrike Zeigermann \\ Department for Political Science, University of Magdeburg, 39106 Magdeburg, Germany; \\ E-Mail: ulrike.zeigermann@ovgu.de
}

Submitted: 5 September 2020 | Accepted: 27 January 2021 | Published: 26 February 2021

\begin{abstract}
Although there is a broad agreement on the importance of scientific knowledge for the implementation of the Sustainable Development Goals, high levels of uncertainty and debate about what counts as knowledge challenge the use of research for political decision-making. Hence, the question arises, which strategies of scientific knowledge integration are adopted by science-based actor-networks that seek to enhance evidence in sustainability governance. In this article, I study the Sustainable Development Solution Network (SDSN) engaged in different institutional settings and policy fields. With a qualitative document analysis, I compare the overall structure, objectives, thematic focus, formal knowledge processes, and outputs of 22 national sub-networks of the global SDSN in order to elucidate how these initiatives integrate contested sustainability knowledge underpinning the implementation of the 2030 Agenda. My findings suggest that most SDSNs adopt solution-oriented knowledge integration strategies but also that networks in countries with better overall SDG performance tend to adopt assessment-oriented and learning-oriented strategies. In reflecting on these results in the context of the current literature on knowledge integration in sustainability governance, I argue that science-policy interfaces are shaped by the intentional and dynamic interactions of actors within their institutional setting and policy environment, and propose pathways for further research.
\end{abstract}

\section{Keywords}

expertise; global actor networks; knowledge integration; knowledge networks; SDG; sustainable development; sustainability governance

\section{Issue}

This article is part of the issue "The 2030 Agenda for Sustainable Development: Transformative Change through Sustainable Development Goals?" edited by Thomas Hickmann (University of Utrecht, The Netherlands), Markus Lederer (Technical University of Darmstadt, Germany), Jens Marquardt (Technical University of Darmstadt, Germany), Sandra Schwindenhammer (Justus Liebig University Giessen, Germany) and Sabine Weiland (Catholic University of Lille, France).

(C) 2021 by the author; licensee Cogitatio (Lisbon, Portugal). This article is licensed under a Creative Commons Attribution 4.0 International License (CC BY).

\section{Introduction}

Understanding how scientific knowledge integration can contribute to the implementation of the 17 Sustainable Development Goals (SDGs) has become increasingly important due to widespread uncertainty and ignorance in sustainability governance (Schneider et al., 2019; United Nations, 2019). 'Scientific knowledge integration' describes the reciprocal and dynamic processes by which scientific research is coupled with political interests and demands from stakeholders in a certain political environment generating outputs that may inform political decision-making (Böcher, 2016, pp. 66-67). One major related challenge is ensuring that all relevant research perspectives and legitimate political interests are represented as knowledge integration occurs in a context of power relations (Böcher \& Krott, 2016; Turnhout, 2018) and deals with complex sustainability problems (Mielke, Vermaßen, \& Ellenbeck, 2017; SAPEA, 2019). Furthermore, it is highly contested whether sustainability research only encompasses scientific knowledge, which is based on scientific theories and methods, or also transdisciplinary and non-scientific (e.g., indigenous) knowledge (Clark, Kerkhoff, Lebel, \& Gallopin, 
2016; Hirsch Hadorn, Bradley, Pohl, Rist, \& Wiesmann, 2006; Jasanoff, 2016).

Against this background, new actors have emerged in order to tackle these challenges and improve scientific knowledge integration in sustainable development governance (Kalafatis, Lemos, Lo, \& Frank, 2015; McGann \& Whelan, 2020; Schmalzbauer \& Visbeck, 2017). In particular, sustainability knowledge networks, such as the FutureEarth Network, the Global Environmental Outlook, or the United Nations Knowledge Platform, have the objective of fostering the exchange between science and political interests for more effective and informed sustainable development governance. Due to their transdisciplinary and transnational structure, they differ from international organizations and epistemic communities, which have traditionally been analysed regarding knowledge processes in global sustainability governance (Sending, 2019). These complex actors are determined by prevailing power structures and therefore adopt different strategies in different regional contexts. However, through their strategic interaction to improve scientific knowledge integration, sustainability knowledge networks inevitably contribute to new power relations which may inadvertently lead to new challenges for informed sustainability governance.

Taking these dynamics as a starting point, this article seeks to contribute to critical reflection on scientific knowledge integration in sustainable development governance by examining how new sustainability networks understand and organize scientific knowledge integration processes. For that purpose, I am operationalizing 'scientific knowledge' in a broad sense that encompasses diverse forms of sustainability research. Although initial studies have analysed how global networks interact at the science-policy interface to translate scientific knowledge for tackling 'wicked problems' in general (e.g., Weber \& Khademian, 2008) and SDG governance challenges in particular (e.g., Van der Hel \& Biermann, 2017), the following question remains unanswered: Which strategies to scientific knowledge integration are adopted in different contexts characterized by diverse institutional settings and sustainability challenges?

In this study, I explore scientific knowledge integration processes focusing on the global Sustainable Development Solution Network (SDSN) and its subnetworks. The global SDSN comprises 36 national and regional sub-networks working on diverse SDG issues (as of November 2020). It was established in 2012 under the auspices of the United Nations Secretary-General to promote integrated approaches to implement the SDGs and the Paris Agreement through education, research, policy analysis, and global cooperation. Although its approach to 'actionable scientific knowledge' and problem solving is gaining increasing prominence with growing numbers of sub-networks and members, "The type and form of solutions coming from science are generally not specified [and] science institutions differ sub- stantially with respect to actor groups that they claim to represent" (Van der Hel \& Biermann, 2017, p. 217). Hence, examining the strategies of SDSN sub-networks in different institutional and political contexts can shed light on how sustainability knowledge networks are dealing with preexisting power relations as well as how they are defining new norms for controversial issues in scientific knowledge integration, i.e., regarding the sustainability focus of science-based policy advice, the definition and selection of sustainability science through their interaction orientation and stakeholder involvement in integration processes.

Based on a qualitative content analysis and manual coding of textual material published by national subnetworks of the global SDSN, I compare their structure, objectives, thematic focus, activities, and outputs in order to elucidate their strategies for scientific knowledge integration. In a second step, I examine the political environments and institutional settings defining the science-policy interface in which those national networks are based and compare that information with the strategies adopted by the networks. My findings suggest that most SDSNs adopt solution-oriented knowledge integration strategies but also that networks in countries with a better overall SDG performance adopt further assessment-oriented and learning-oriented strategies. Hereby, I explain the ways in which political contexts and the strategic interactions of knowledge networks are linked.

\section{Analysing Scientific Knowledge Integration in Sustainability Governance}

To operationalize the aim of this study, I draw on knowledge transfer theory explaining the production, translation, diffusion, and circulation of diverse forms of knowledge, including science, across different political actors, levels, fields, or institutional settings. Hence, it allows one to define scientific knowledge integration strategies in sustainability governance (Section 2.1) and the role of institutional structures (Section 2.2).

\subsection{Strategies for Scientific Knowledge Integration for Sustainable Development}

As the 17 SDGs of the Agenda 2030 intend to bring together different political positions regarding the contested concept of sustainable development, it is not surprising that various conflicts and incoherence exist across the SDGs (Breuer, Janetschek, \& Malerba, 2019; McGowan, Stewart, Long, \& Grainger, 2019) and, as a consequence, that actors in sustainability governance focus on different thematic priorities and social, environmental and economic objectives. At the same time, there is a broad consensus that the implementation of the SDGs and sustainable development more broadly require scientific knowledge to inform sustainability policies (United Nations, 2019). 
Literature suggests that there are different 'frames' or 'cultures of evidence' for different thematic priorities (Lorenc et al., 2014; Sjöstedt \& Kleinschmit, 2015). Accordingly, institutional structures and activities in one thematic area, such as energy, create specific opportunities and challenges for the integration of scientific and other forms of knowledge into policies, which might differ from those in other thematic areas. Against this backdrop, actors at the science-policy interface may focus on: (a) the implementation gap by assessing deficit requirements regarding specific sustainability goals; (b) SDG incoherences and priority-setting for sustainable development by analysing processes and instruments for the coordination of competing political interests; (c) independent sustainability research to inform policymaking; or (d) deliberation of the values underlying sustainable development (Zeigermann, 2020). This is categorized as sustainability focus in the present study and reflected in 'utilisation products' (Böcher \& Krott, 2016, p. 34), that political actors may use for political decision-making. These 'utilization products' or outputs address different stakeholders, including (a) those actors related to a specific problem with recommendations and policy advice, (b) a more general political discourse through the communication and translation of science-based solutions for sustainable development, (c) an academic audience with independent analysis and interdisciplinary assessments, or (d) a general public with learning tools and deliberation approaches (Arnott, Neuenfeldt, \& Lemos, 2020; Nederhand, Steen, \& Twist, 2019). The orientation towards specific stakeholders is categorized as target groups of scientific knowledge integration processes in this study.

By 'scientific knowledge integration' I mean the reciprocal and dynamic processes by which 'bricks of knowledge' from scientific research are chosen because both researchers and practitioners consider them politically relevant (Böcher \& Krott, 2016, p. 34). Evidence from scientific research is hereby translated and transferred as it is applied to different institutional and political contexts (Clark et al., 2016; Rawluk, Ford, Little, Draper, \& Williams, 2020). At the same time, local experiences and interests of stakeholders for evidence-based solutions are selected and reformulated into new questions for academic research (Hirsch Hadorn et al., 2006; Mielke et al., 2017). This requires compromise and trade-offs regarding the impact of scientific research and practical demands for solutions to problems (Mielke, Vermaßen, Ellenbeck, Fernandez Milan, \& Jaeger, 2016; Reed et al., 2009). Hence, at the centre of these scientific knowledge integration processes in sustainability governance are interactions of diverse actors from the research sphere and the political sphere. They seek to increase their authority through salience, legitimacy, and credibility (Cash et al., 2003, p. 8086). Accordingly, the interactions of actors are oriented towards specific stakeholders, which lead to different forms of cooperation with diverse 'allies' (Böcher \& Krott, 2016, pp. 45-46), different forms of stakeholder engagement (Meadow et al., 2015, p. 183) and different approaches to authority in political processes (Cash et al., 2003, p. 8086). We can thereby distinguish activities that are: (a) oriented towards internal allies legitimizing integration outputs through recognized expertise, credibility and salience in a specific field; (b) oriented towards external allies in politics that contribute to timely problem-solutions through their participation; (c) oriented towards wise allies who are open to comprehensive scientific assessments, prognoses and (peer) review; and (d) learning allies who represent very diverse interests, participate in deliberation processes and can develop alternatives to current approaches to sustainable development (Böcher \& Krott, 2016, pp. 50-52). This is operationalized as interaction orientation in the present study.

Summing up, we identify three main categories that provide us with the first part of a conceptual basis to examine the strategies of sustainability knowledge networks: (a) sustainability focus; (b) target-groups; and (c) interaction orientation. These elements are reflected in the objectives, thematic priorities, activities, structures, and outputs of actors at the science-policy interface. This framework is grounded in the RIU model for scientific knowledge transfer (Böcher \& Krott, 2016) merging the attributes 'orientation towards public goals' and 'relevance in regard to political processes' of scientific knowledge integration (Böcher \& Krott, 2016, pp. 50-52) into the category 'sustainability focus' of sustainability knowledge networks according to my research interest.

\subsection{Scientific Knowledge Integration Processes Embedded in Institutional Structures}

Given the multiple strategies for scientific knowledge integration, the objective of this study is not only to identify dominant strategies in different sustainability knowledge networks but also to examine the role of the institutional setting and policy environment. Although all countries agreed to the 17 SDGs in the United Nations General Assembly in 2015, they defined different priorities in their national sustainability strategies. They also vary in their efforts and performance in implementing these goals at the regional and local levels (Sachs et al., 2020). Furthermore, there is variation in the state of a country's democracy and governance, including, in particular, the extent to which citizens are able to participate in the selection of their government and express their interests in political decision-making through guaranteed rights and freedoms.

Considering that rational interactions of actors may influence institutional settings, while institutions and political environments also influence actor interactions (Scharpf, 1997), these prerequisites determine actor constellations and decision-making processes, including stakeholders and allies in sustainable development governance as well as the role that science plays in society 
and politics. In other words, drawing on the concept of 'bounded rationality,' actors are assumed to act rationally within the boundaries of their capabilities (structural limitations) and available information (cognitive limitations; Scharpf, 1997). They seek to maximize the impact of their interaction at the science-policy interface and contribute to sustainable development through enhanced interaction between science and politics. Their political environment determines the boundaries of their interaction and can therefore be seen as a factor contributing to specific strategies to scientific knowledge integration processes across different countries (Ladd \& Ward, 2002). Actors are likely to not only place different emphasis on disciplinary and interdisciplinary scientific knowledge that is based on recognized academic standards and methods (in contrast to or in combination with experiential knowledge and transdisciplinary research) but they may also face different challenges for scientific knowledge integration. Institutional settings and the policy environment may therefore both promote and hamper the ways in which scientific knowledge is transferred and used in political decision-making processes.

Taken together, these theoretical considerations highlight the importance of studying strategies of actors for scientific knowledge integration in relation to their political environment. This is an important gap in the literature as studies have-to my knowledge-focused so far either on strategies for scientific knowledge integration in sustainability governance (Cash et al., 2003) or on scientific knowledge integration processes more generally in different institutional and political contexts (Do, Krott, \& Böcher, 2020). The objective of this article is to add to the literature on scientific knowledge integration by combining these two perspectives with an empirical study.

\section{Research Data and Methods}

This article undertook a structured comparison of 22 national knowledge networks engaged in governance processes for sustainable development in diverse political environments, with data collected from March 2019 until August 2020. As defined in the introduction, these networks are understood as complex actors at the science-policy interface, which adopt different strategies for scientific knowledge integration (cf. assumption of bounded rationality) in different political contexts (cf. assumption of interrelationship between actors and institutions).

\subsection{Case Selection}

While research has traditionally assessed scientific knowledge integration processes in global sustainability governance of international organizations (Siebenhüner, 2008; Zeigermann \& Böcher, 2019) and epistemic communities (Carayannis, Pirzadeh, \& Popescu, 2011; Haas, 2015), sustainability knowledge networks are particu- larly relevant for empirical analysis as they represent new actors at the science-policy interface. They can be understood as complex actors with a formal and institutionalized structure. Their main objective is to increase the exchange between scientific research and political interests and to promote science-based political decisionmaking for sustainable development. For that purpose, they interact with a diverse range of sustainability researchers and political actors in different political contexts (Van der Hel \& Biermann, 2017; Zeigermann, 2020), which makes them a relevant research object for the study of strategies at diverse science-policy interfaces.

In order to add to existing research on global sustainability knowledge networks (Lahsen et al., 2013; Sending, 2019), this study focuses on the SDSN, which epitomize the new networks seeking to mobilize sustainability research for developing solutions for the implementation of the SDGs through their cooperation with political actors (Van der Hel \& Biermann, 2017; Zeigermann, 2020). It is characterized by a formal global structure comprising 25 national sub-networks, working in different political environments. The formally independent and yet closely connected sub-chapters of the global SDSN represent a great variety of socio-economic environments, in which the political commitment to and realisation of the SDGs is very different. In particular, the varying SDG performance provides for a different political environment in which the national SDSNs interact at the science-policy interface. Among these 25 national networks, 22 were selected for this analysis. Three national SDSNs (SDSN Kenya, Thailand, and Cyprus) were excluded from the analysis as they were only founded in 2020 and the available information was not sufficient for a systematic comparative analysis. This case selection allows us to find out whether different strategies to scientific knowledge integration are adopted by the national sub-networks in their respective political environments to contribute to common overall objectives of the global SDSN.

The coloured countries in Figure 1 represent the 22 SDSN sub-networks and the SDG performance of their political environment in order to highlight their diverse contexts. Differences regarding the implementation of the SDGs can be determined by assessing the information provided in the 2020 Sustainable Development Report (Sachs et al., 2020), the Sustainable Development Goals Report 2020 (United Nations, 2020), and SDG Country Profiles as presented in the United Nations Stats Hub. Those countries classified among the 'top $20^{\circ}$ in the SDG ranking are generally considered to be those with a high SDG performance, although this ranking only reflects available information at a very high level of aggregation, which might obscure sectoral or regional differences. Similar limitations need to be taken into account and critically reflected in definitions of national governance systems. Yet, indicators, like the Human Development Index or Country Profiles and Governance Indicators from the World Bank and The Global State 


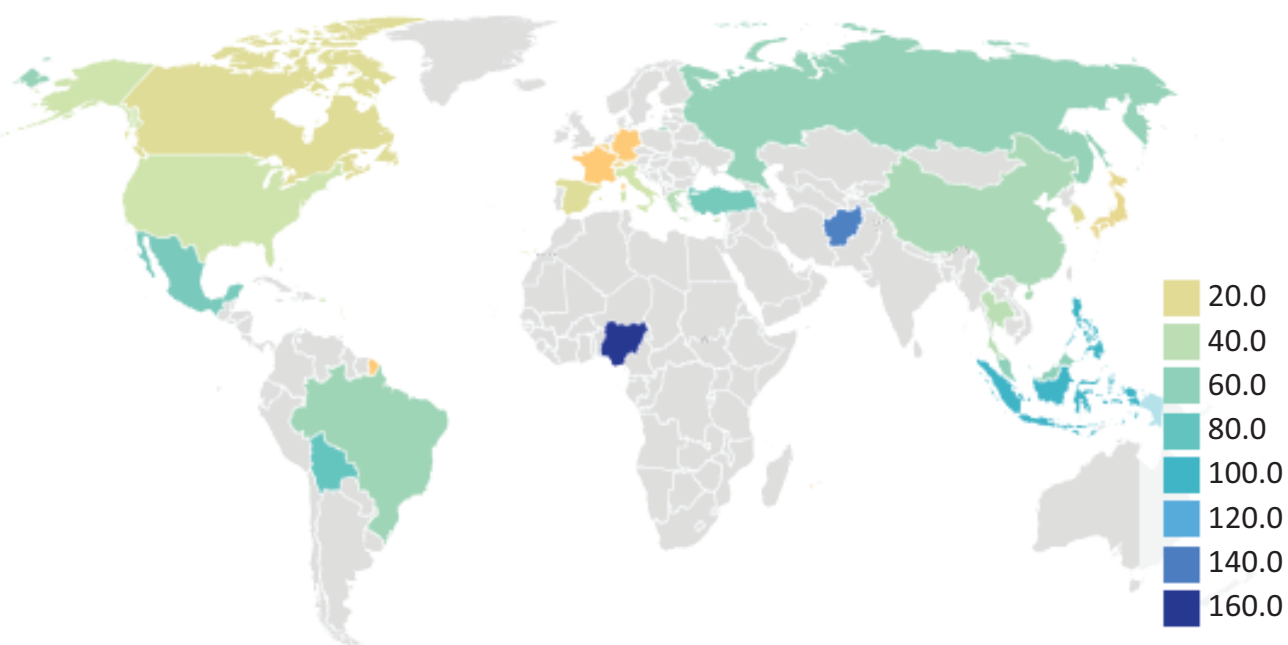

Figure 1. National SDSNs around the world coloured according to their SDG performance. Notes: SDG ranking as presented in Sachs et al. (2020). Colours represent SDG ranking of 193 states (1-20 being the best). Map: Created with Datawrapper based on information on national SDSNs from the global SDSN website, 2020.

of Democracy Indices provide valuable aggregated information based on quantitative data, that can be used to compare countries in terms of their level of democratic decision-making and also in regard to capabilities of actors to influence science-policy interaction.

\subsection{Data Collection and Qualitative Content Analysis}

For the empirical study of scientific knowledge integration strategies across 22 national SDSNs, a structured qualitative analysis of documents was undertaken using the software MAXQDA in order to identify the perception the SDSN has of their own strategy (by studying objectives and structures as presented by the networks). This approach allows one to understand the thematic priorities and orientation of activities (i.e., by studying the outputs and action reports of the networks). Accordingly, I analysed documents produced by the 22 national SDSNs, such as SDSN Networks in Action Reports (2017-2019), audited financial statements (2016-2019), and formal information on the global SDSN Association, as well as 54 monthly newsletters from the global SDSN and 37 websites from SDSNs and their host institutions. Published outputs since 2012, including reports, issue briefs, or policy papers on SDG issues, such as agriculture (10), cities (12), climate and energy (8), education (2), extractive and land resources (5), food and biodiversity (4), happiness (6), health (7), the SDG Academy (2), SDG financing (14), SDG Indices and Dashboards (25, overlaps), SDSN Youth (2), TReNDS in data and statistics (10) and the world in 2050 (3), provided an understanding of the activities of the different networks.

In order to examine which approach to scientific knowledge integration is adopted in a national SDSN network, I segmented the documents into relevant categories by making use of a systematic coding process (inspired by Kuckartz, 2010). According to my theoretical considerations, textual fragments were grouped into categories dealing with structure, objectives, thematic priorities and (intended) outputs (inspired by Sarkki et al., 2015). This factual information was then used to define the overall characteristics of a network in regard to its sustainability focus, target-groups and interaction orientation in regard to allies as defined in Section 2.1. I compared the similarities and differences across these 22 networks in order to identify groups of countries with similar strategies to scientific knowledge integration. This analysis served to identify the different strategies that are presented in Section 4.1. While such classification of overall groups necessarily requires abstraction and simplification from a more complex reality, it also allowed me to identify commonalities and differences across the different cases regarding their political context.

In order to analyse which strategies for scientific knowledge integration are adopted in different socioeconomic and environmental environments, I compared the 22 cases by putting the findings regarding their chosen knowledge integration strategy alongside the cases' respective political context. More precisely, I compared the SDG performance and governance systems of the cases with similar scientific knowledge integration strategies. Although governance structures and SDG performance may differ across regions within a country or in regard to specific policy areas, quantitative indicators (such as the Human Development Index and Governance Indicators from the World Bank or the Sustainable Development Report) provide a valuable characterisation of national political contexts, which is suitable for the objective of this study. It allows us to identify similarities and differences across networks that are embedded in diverse national political contexts, and it may also serve as a starting point for other in-depth analyses. 


\section{Comparing the Science: Policy Interface across SDSNs}

With my empirical analysis, I can identify the strategies adopted in 22 sustainability knowledge networks to promote scientific knowledge integration in sustainable development governance: solution-oriented, assessment-oriented, and learning-oriented strategies (Section 4.1). In a second step, I will link the identified strategies of scientific knowledge integration to the political environment of the networks (Section 4.2).

\subsection{Dealing with Contested Knowledge through Different Knowledge Integration Processes}

National SDSNs generally emphasize that they seek to "translate the latest expertise in sustainable development into action" (United Nations SDSN, 2020). For that purpose, most hosting SDSN research institutes address external partners from public or private agencies, civil society or youth groups through participatory events and publications (e.g., workshops, forums, policy briefs, webinars). Such events allow them to collaborate, launch solution initiatives and localize support for the SDGs (cf. interaction orientation oriented towards external allies in politics that contribute to timely problem-solutions through their participation). However, while some networks primarily focus on external allies, other networks set other priorities and can therefore be classified as another approach to scientific knowledge integration.

The comparison shows that the networks in Afghanistan, Brazil, China, Russia, Malaysia, Mexico, Turkey, Bolivia, Philippines, Nigeria, and Indonesia target a more general political discourse through the communication and translation of science-based solutions for sustainable development to external partners. For instance, SDSN Malaysia stresses that it "aims to mobilize a community of experts and influencers to translate ideas and expertise into practical action towards the sustainable development for the country" (SDSN Malaysia, 2020). It works together with various stakeholders from all regions in Malaysia representing a variety of relevant sectors and has included nine of them in their Leadership Council to take on SDG responsibility and guide its work. While SDSN Brazil cooperates for that purpose notably with local partners from the Rio de Janeiro region, SDSN Mexico collaborates, among others, with the Mexican Government and the German Development Agency, and SDSN Turkey with the G20. Hereby, stakeholder communication through social media, formal and informal communicative channels play an important role. It serves to link SDG evidence in a timely and adequate manner with political processes, political priorities, and issues discussed in the national and international discourse. In that regard, SDSN Turkey has, for instance, contributed to the Istanbul Climate Action Plan; most SDSN networks have Twitter accounts to disseminate their output and to react to current political debates, and SDSN Russia has organized roundtables and workshops as well as academic papers to "translate the SDGs to the Russian context by providing top-notch research, boosting youth leadership, and engaging in a wide array of projects and partnerships to prepare the country for the achievement of the 2030 Agenda" (SDSN Russia, 2020). By engaging in those knowledge processes, the SDSN networks implicitly acknowledge that different stakeholders have different-often even conflictinginterests regarding SDGs. Hence, they propose SDG information and evidence-based solutions with a clear sustainability orientation that are discussed in relation to current political problems. More generally, they focus on SDG incoherences and priority-setting for sustainable development by analysing processes and instruments for the coordination of competing political interests. SDSN Bolivia states, for instance, that "the overarching objective of SDSN-Bolivia is to promote sustainable visions and solutions for long-term development in Bolivia" (SDSN Bolivia, 2020). It seeks to actively produce and share innovations on the SDGs across the different municipalities in Bolivia by providing data in an atlas, newsletters, a blog, tweets, and workshops on municipal SDG challenges, and with a strategic alliance with the Municipal Association of Bolivia. This approach to contested sustainability knowledge across different municipalities, sectors, and national contexts with practice-oriented innovations and strategic knowledge transfer with external allies can be seen as a solution-oriented approach to scientific knowledge integration.

While also supporting evidence-based solutions for sustainable development through activities that are oriented towards external allies and coordination of SDG incoherences, other national SDSN networks are pursuing different priority activities in order to develop science-based advice based on inter- and transdisciplinary assessments that systematically integrate scientific knowledge so as to represent a state-of-the-art in sustainability research. More precisely, their interaction is mainly aimed at wise allies who are open to comprehensive scientific assessments, prognoses and (peer) review. For instance, SDSN Greece adopts solutionoriented strategies as outlined above by establishing an SDSN EU Green Deal Senior Working Group for the Energy Transition which "will support the implementation of the European Green Deal and facilitate the participation of national stakeholders and local experts through SDSN's European networks to advise and provide support to the European Commission" (SDSN Greece, 2020) or by using its so-called 'systems innovation approach' to launch the Global Roundtable for Sustainable Shipping and Ports at the COP25 in December 2019 in Madrid. However, it has also established several assessment initiatives, such as the ReSEES which is made up of international research projects and publications produced by an interdisciplinary and international research team, diverse Horizon 2020 and other research projects 
under the umbrella of Athena Research and Innovation Centre or the International Centre for Research on the Environment and the Economy (cf. sustainability focus on independent sustainability research to inform policymaking). Similarly, SDSN Spain, SDSN Italy, SDSN South Korea, and SDSN USA not only address the political discourse by translating scientific evidence into practical solutions, but they also offer scientific review and prognoses, including by producing Spanish, Italian, European, and USA City SDG Indices, and by participating in the Deep Decarbonization Pathways Project or, as for SDSN South Korea, by coordinating the Mid-Latitude Region Network, which promotes research activities particularly on Food-Water-Ecosystem resilience. Hence, their activities are mainly oriented towards an academic audience with independent analysis and interdisciplinary assessments. To summarize, these networks not only seek to foster sustainability solutions (solution-based approach) but they principally appeal to the academic discourse integrating different research perspectives and pursuing an assessment-oriented approach to contested scientific sustainability knowledge in politics.

Finally, there are those national SDSN that focus on learning processes through inclusive partnerships and deliberation of alternative sustainability solution pathways, norms, and interests for SDG governance in addition to promoting evidence-based sustainability solutions. They primarily focus on the deliberation of values underlying sustainable development. The open target-group orientation towards learning tools and processes can be illustrated in the transdisciplinary working group structure; the development and deployment of the Sustainability Literacy Test (Sulitext) in SDSN France; the emphasis on dialogue and cooperative formats by SDSN Germany which also contributes to the German Science Platform Sustainability 2030; or the fact that SDSN Switzerland noted in its objectives that it seeks to "shape multistakeholder dialogue [by accelerating] continuous exchange of ideas and experiences and create thinking spaces for the scientific community, government, business and civil society to foster systemic solutions, build commitment and mobilize action" (SDSN Switzerland, 2020), with its Circular Resources Lab. In order to promote learning among diverse stakeholders for SDG implementation, SDSN Japan has, for instance, developed Guidelines for multi-stakeholder partnerships to implement the 2030 Agenda in Asia and the Pacific (SDSN Japan), and SDSN Canada has built a "pan-Canadian network of post-secondary institutions, civil society, and others, to facilitate learning and accelerate problem solving for sustainable development" (SDSN Canada, 2020). In other words, their interaction is primarily aimed at learning allies who represent very diverse interests, participate in deliberation processes and can develop alternatives to the current approaches to sustainable development. To summarize, while it is not surprising that all national SDSN networks seek to contribute to science-based sustainability solu- tions (Zeigermann, 2020), it is important to note differences in national priorities across the networks.

\subsection{The Role of the Policy Environment for Knowledge Integration Processes in SDG Governance}

Looking at the diversity of knowledge strategies chosen by the analysed country networks, the question now is: Which factors account for this diversity? Many SDSN networks note in their so-called 'vision' that one of their main knowledge-related areas of work consists of mainstreaming SDGs by addressing institutional awareness (e.g., SDSN Afghanistan, 2020). Without explicitly referring to the institutional and political setting, networks note that they want to increase 'SDG awareness' and for that purpose, they not only strive to bring multiple public and private stakeholders together, but also to "translate knowledge on the SDGs into organizational processes" (e.g., SDSN Belgium, 2020); link their activities to "official SDG processes" (e.g., SDSN Indonesia, 2020); and "assist governments in identifying local, national, and regional sustainability challenges" (e.g., SDSN Russia, 2020).

The comparison across the cases with similar knowledge integration strategies, as presented in the previous section, shows that SDSN networks in countries with relatively stable and democratic structures (as measured in the 2019 Worldwide Governance Indicators) and relatively good sustainable development performance (as measured by their performance in the realization of the SDGs) are those that primarily pursue assessmentoriented and learning-oriented strategies for scientific knowledge integration. For instance, SDSN Switzerland, Canada, Germany, France, Belgium, and Japan with their learning-oriented strategies to scientific knowledge integration interact in a political environment characterized by relatively high implementation of the SDGs and overall political support for sustainable development by political actors (Sachs et al., 2020; United Nations, 2020). These countries are ranked among the top 20 (out of 193 countries) in the 2020 Sustainable Development Report. Spain, Italy, Greece, the USA, and the Republic of Korea, in which SDSN networks adopt mostly assessmentoriented strategies, are ranked among the top 50 (out of 193 states). According to the regional groupings of the United Nations (United Nations, 2020), countries that focus on assessment-oriented and learning-oriented strategies are attributed to the group 'Europe and North America' (except for Japan and South Korea; United Nations, 2020, p. 63). Both, the 2020 United Nations SDG report and the 2020 Sustainable Development report found that this group of countries is performing relatively well in terms of most SDGs but that challenges persist particularly in terms of SDG 13 (climate action), which addresses the ecological dimension of sustainable development. This relative lack of sustainability politics to tackle climate change reveals a structural problem of those countries from high-resource and high-consumption contexts, which thus make the 
issue very hard to address. The assessment-oriented and learning-oriented strategies of national SDSN networks in Europe and North America, Japan, and South Korea indicate that these networks seek to foster scientific knowledge integration in sustainability politics therefore by appealing to wise allies and learning allies in order to contribute to sustainable societal change through understanding and learning based on scientific evidence. This also means to deliberate fundamental questions pertaining to the concept of sustainable development and to mitigate across conflicting political interests in problematic preexisting power structures that hamper, for instance, effective climate action.

Hence, stable democratic institutional settings in countries (especially possibilities for political participation of multiple stakeholders and political accountability as assessed in Voice and Accountability Percentile Rank of the Worldwide Governance Indicators; economic prosperity, education and well-being as assessed in the Human Development Index) seem to enable assessmentoriented and learning-oriented strategies to scientific knowledge integration that may contribute to fundamental political change towards sustainable development. In contrast, SDSN network in other relatively less open, inclusive, accountable, and less democratic countries (according to the Human Development Index and the Worldwide Governance Indicators) that are performing less well in terms of sustainable development and the implementation of the SDGs (Sachs et al., 2020; United Nations, 2020), have mostly adopted solutionoriented strategies which promise immediate effects through the support of powerful external allies in politics rather than long-term societal and political transformation. Hence, their interaction is mainly oriented towards political decision-makers and powerful private and civil society stakeholders (cf. 'external allies'; Böcher \& Krott, 2016, p. 36) which can directly influence political decision-making through policy entrepreneurship (Brouwer \& Huitema, 2018). Figure 2 illustrates that link between the political environment and strategies of national SDSN networks drawing on information from the 2020 Sustainable Development Report and the 2019 World Governance indicators. Patterns across national SDSN networks indicate correlations of the political contexts and scientific knowledge integration strategies.

In these diverse political contexts, national SDSN networks are engaged in different thematic fields, thereby adopting either a more explicit thematic focus (e.g., SDSN Belgium, SDSN Brazil, SDSN Canada, SDSN France, SDSN Greece, SDSN Malaysia, SDSN Nigeria, SDSN Philippines, SDSN Spain, SDSN Switzerland) or more general, knowledge integration-related priorities (e.g., SDSN Afghanistan, SDSN Bolivia, SDSN Germany, SDSN Italy, SDSN Japan, SDSN Russia, SDSN Turkey, SDSN USA). Thematic priorities are generally linked to the following policy fields: education, energy and climate, landuse and water, biodiversity, and urban development. As research institutions lead SDSN activities in cooperation with other partners, it is not surprising that educational activities, including summer schools, seminars, online learning courses, contributions to the SDG Academy, webinars, and research projects are among the

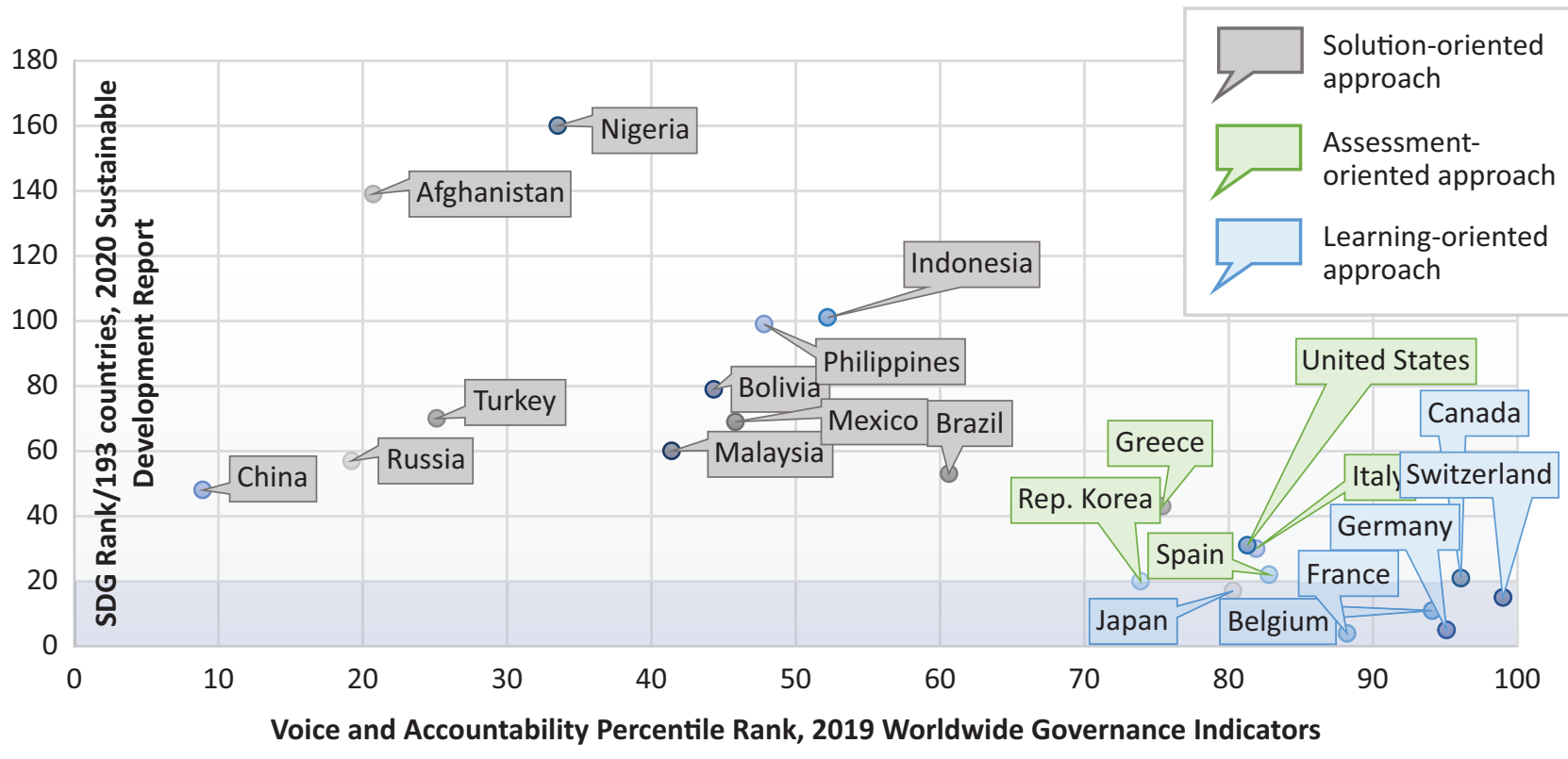

Figure 2. Knowledge processes of national SDSN networks in different policy environments. Notes: Country names represent SDSN networks. The SDSN networks marked in grey are those with a primarily solution-oriented approach to scientific knowledge integration. The SDSN networks marked in green stand out for their assessment-oriented approach and those SDSN networks marked in blue focus on a learning-oriented approach. Sources: 2019 Worldwide Governance Indicators (The World Bank, 2020), 2020 Sustainable Development Report (Sachs et al., 2020), findings from Section 3.1. 
main activities through which national SDSNs seek to contribute to SDG knowledge production and transfer of sustainability evidence. As indicated before, other thematic priorities of a national SDSN network can often be linked to SDG challenges of a country (as identified in the annual Sustainable Development Report). For instance, SDSN Belgium explicitly focuses in its activities on climate change, energy, chemistry, and institutions, which can be related to the SDG challenges of the country (especially regarding SDGs 12, 13 and 14; Sachs et al., 2020).

\section{Discussion of Findings}

The comparison of 22 national SDSN networks has indicated that the 'solution-oriented' strategy to scientific knowledge integration, which was identified as the overall approach of the global SDSN (Van der Hel \& Biermann, 2017; Zeigermann, 2020), varies across the sub-networks (see Table 1). This variation ranges from minor adaptation towards different strategies for knowledge integration in sustainable development governance. Hereby, my analysis adds to the literature on new actors at the science-policy interface (especially McGann \& Whelan, 2020; Sending, 2019) showing that sustainability knowledge networks in countries with a better overall SDG performance and stable democracies tend to focus on assessment-oriented and learning-oriented strategies, whereas networks in other countries tend to adopt solution-oriented strategies (Table 1).

The typology of scientific knowledge integration strategies (Table 1) confirms previous studies on scien- tific initiatives in sustainability governance. At the same time, the 'advice-oriented' strategy as a more classical strategy for informing politics (Van der Hel \& Biermann, 2017) could not be identified as a dominant approach of national SDSN networks. This indicates that the networks seek to advance new strategies that they consider to be more effective in regard to contested scientific knowledge integration in sustainability governance. At this point, it is important to note that this study does not assess the actual effects of strategic interactions of sustainability knowledge networks in national sustainability governance. However, in order to conduct such an analysis, which appears highly relevant regarding problematic and changing power relations at the science-policy interface in sustainability governance, it is necessary to identify and explicate dominant strategies in a first place. This was the purpose of my analysis.

Regarding the strategies presented in Table 1 , it should also be emphasised that reality is certainly more complex than the three main strategies for scientific knowledge integration of the SDSN networks identified in my analysis. Developing a typology always requires a reduction in complexity and, while allowing one to gain a better overall understanding of the use of scientific knowledge in different political contexts for sustainability governance, there are also limitations to this study: First, the identification of an overall strategy of national SDSN networks was not always clear-cut, as their structure, objectives, thematic priorities, and outputs could sometimes be attributed to several thematic and analytical codes. Hence, additional information (e.g., from

Table 1. Scientific knowledge integration strategies in national SDSN networks.

\begin{tabular}{llll}
\hline Strategy & Solution-oriented strategy & Assessment-oriented strategy & Learning-oriented strategy \\
\hline Sustainability & SDG incoherences and & Independent sustainability & Deliberation of the values \\
focus & priority-setting for sustainable & research to inform & underlying sustainable \\
& development by analysing & policymaking & development
\end{tabular}
processes and instruments for the coordination of competing political interests

Target groups A more general political discourse through the communication and translation of science-based solutions for sustainable development

Interaction orientation

Oriented towards external allies in politics that contribute to timely problem-solutions through their participation

Examples
SDSN Brazil, Mexico, Malaysia, Bolivia, Philippines, Indonesia, Turkey, Russia, China, Afghanistan, Nigeria
An academic audience with independent analysis and interdisciplinary assessments

Oriented towards wise allies who are open to scientific assessments, prognoses and (peer) review

SDSN Greece, South Korea, USA, Italy, Spain
A general public with learning tools and deliberation approaches

Oriented towards learning allies representing very diverse interests and participate in deliberation processes

SDSN Belgium, Canada, France, Germany, Japan, Switzerland 
interviews) but also an adaptation of analytical concepts with a more nuanced analysis of the orientation of these networks towards political processes and intermediation might reveal useful information. Second, more scientific evidence from other sustainability knowledge networks engaged in different political contexts is needed to critically assess my findings in light of information derived from a broader database. Future research may, for instance, consider adopting a network approach to disentangle the extent to which cooperation at different political levels and across different sectors takes place via sustainability knowledge networks. Third, studying scientific knowledge integration processes also requires a thorough analysis of the 'knowledge' (i.e., scientific evidence from certain disciplines, using specific methods and dominant theoretical approaches) used by actors at the science-policy interface rather than other scientific or experiential knowledge.

By analysing scientific knowledge integration activities and outputs of national SDSN networks in light of their political context, my study elucidates the relationship between sustainability knowledge networks and their institutional setting. It adds to the analysis of science-based actors in sustainability governance by adopting a novel approach inspired by the 'actor-centred institutionalism,' according to which actors and institutions influence one-another (Scharpf, 1997). I argue that broad acceptance of the role of (sustainability) science in political decision-making, of political sustainability goals and of democratic decision-making standards contribute to more inclusive scientific knowledge integration strategies, i.e., targeting a broad (inter- and transdisciplinary) academic audience and the general public through assessment and learning. In light of existing power structures, which may hamper sustainability governance, assessment- and learning-oriented strategies of actors at the science-policy interface can potentially increase the salience and legitimacy of sustainability science, and of the implementation of the SDGs more broadly, by transparently tackling underlying conflicting values, norms, and interests. Solution-oriented strategies, on the other hand, can contribute to the timely resolution of problems which may increase the general awareness of and support for sustainability. Hence, different priorities regarding scientific knowledge integration in sustainability governance as well as different capabilities of the networks may explain why the political environment and democratic structure of a country correlates with the strategic interaction of actors at the science-policy interface.

\section{Conclusions}

Widespread uncertainty and contestation of scientific expertise in sustainable development governance underline the importance of studying scientific knowledge integration processes. These processes are shaped by the interaction of actors at the science-policy interface
(Böcher \& Krott, 2014, 2016). The emergence of new sustainability knowledge networks will therefore influence the implementation of the SDGs that relies on balancing diverse political interests and sustainability knowledge. They are defined as complex actors with a formal transdisciplinary and transnational structure seeking to improve scientific knowledge integration in sustainable development governance.

This article highlights that the strategies of sustainability knowledge networks differ according to their specific political context. Although the qualitative research design does not allow for systematic assessment of causation or impact, it provides support that science-policy interfaces in countries are influenced by the intentional and dynamic interactions of actors who adapt to their institutional setting and political environment in order to increase their effectiveness (Cash et al., 2003; Clark et al., 2016; Lux et al., 2019; Meadow et al., 2015; Van der Hel \& Biermann, 2017). As such, this article sets the foundation for future research studying the potential effects of sustainability knowledge networks on actor constellations, processes, and power relations at the science-policy interface in sustainability governance and on the implementation of the SDGs.

\section{Conflict of Interests}

The author declares no conflict of interests.

\section{References}

Arnott, J. C., Neuenfeldt, R. J., \& Lemos, M. C. (2020). Co-producing science for sustainability: Can funding change knowledge use? Global Environmental Change, 60.

Böcher, M. (2016). How does science-based policy advice matter in policy making? The RIU model as a framework for analyzing and explaining processes of scientific knowledge transfer. Forest Policy and Economics, $68,65-72$.

Böcher, M., \& Krott, M. (2014). The RIU model as an analytical framework for scientific knowledge transfer: The case of the 'decision support system forest and climate change.' Biodiversity and Conservation, 23, 3641-3656.

Böcher, M., \& Krott, M. (2016). Science makes the world go round: Successful scientific knowledge transfer for the environment. Cham: Springer International Publishing.

Breuer, A., Janetschek, H., \& Malerba, D. (2019). Translating Sustainable Development Goal (SDG) interdependencies into policy advice. Sustainability, 11(7).

Brouwer, S., \& Huitema, D. (2018). Policy entrepreneurs and strategies for change. Regional Environmental Change, 18(5), 1259-1272.

Carayannis, E. G., Pirzadeh, A., \& Popescu, D. (2011). Institutional learning and knowledge transfer across epistemic communities: New tools of global governance. Cham: Springer. 
Cash, D. W., Clark, W. C., Alcock, F., Dickson, N. M., Eckley, N., Guston, D., . . Mitchell, R. B. (2003). Knowledge systems for sustainable development. Proceedings of the National Academy of Sciences of the United States of America, 100(14), 8086-8091.

Clark, W. C., Kerkhoff, L. v., Lebel, L., \& Gallopin, G. C. (2016). Crafting usable knowledge for sustainable development. Proceedings of the National Academy of Sciences, 113(17), 4570-4578.

Do, T. H., Krott, M., \& Böcher, M. (2020). Multiple traps of scientific knowledge transfer: Comparative case studies based on the RIU model from Vietnam, Germany, Indonesia, Japan, and Sweden. Forest Policy and Economics. https://doi.org/10.1016/j.forpol. 2020.102134

Haas, P. M. (2015). Epistemic communities, constructivism, and international environmental politics. Abingdon: Routledge.

Hirsch Hadorn, G., Bradley, D., Pohl, C., Rist, S., \& Wiesmann, U. (2006). Implications of transdisciplinarity for sustainable research. Ecological Economics, 60, 119-128.

Jasanoff, S. (2016). Contested boundaries in policyrelevant science. Social Studies of Science, 17(2). https://doi.org/10.1177/030631287017002001

Kalafatis, S. E., Lemos, M. C., Lo, Y.-J., \& Frank, K. A. (2015). Increasing information usability for climate adaptation: The role of knowledge networks and communities of practice. Global Environmental Change, 32, 30-39.

Kuckartz, U. (2010). Einführung in die computergestützte Analyse qualitativer Daten [Introduction to computer-assisted analysis of qualitative data]. Cham: Springer.

Ladd, D. A., \& Ward, M. A. (2002). An investigation of environmental factors influencing knowledge transfer. Journal of Knowledge Management Practice. http://www.tlainc.com/articl38.htm

Lahsen, M., Bustamante, M., Swap, R., McNie, E., Ometto, J., Schor, T., . . . Annegarn, H. (2013). The contributions of regional knowledge networks researching environmental changes in Latin America and Africa: A synthesis of what they can do and why they can be policy relevant. Ecology and Society, 18(3). http://dx.doi.org/10.5751/ES-05614-180314

Lorenc, T., Tyner, E. F., Petticrew, M., Duffy, S., Martineau, F. P., Phillips, G., \& Lock, K. (2014). Cultures of evidence across policy sectors: Systematic review of qualitative evidence. European Journal of Public Health, 24(6), 1041-1047.

Lux, A., Schäfer, M., Bergmann, M., Jahn, T., Marg, O., Nagy, E., . . . Theiler, L. (2019). Societal effects of transdisciplinary sustainability research: How can they be strengthened during the research process? Environmental Science \& Policy, 101, 183-191.

McGann, J. G., \& Whelan, L. C. (2020). Global think tanks: Policy networks and governance. Abingdon: Routledge.
McGowan, P. J. K., Stewart, G. B., Long, G., \& Grainger, M. J. (2019). An imperfect vision of indivisibility in the Sustainable Development Goals. Nature Sustainability, 2(1), 43-45.

Meadow, A. M., Ferguson, D. B., Guido, Z., Horangic, A., Owen, G., \& Wall, T. (2015). Moving toward the deliberate coproduction of climate science knowledge. Weather, Climate, and Society, 7(2), 179-191.

Mielke, J., Vermaßen, H., \& Ellenbeck, S. (2017). Ideals, practices, and future prospects of stakeholder involvement in sustainability science. Proceedings of the National Academy of Sciences, 114(50), E10648-E10657.

Mielke, J., Vermaßen, H., Ellenbeck, S., Fernandez Milan, B., \& Jaeger, C. (2016). Stakeholder involvement in sustainability science: A critical view. Energy Research \& Social Science, 17, 71-81.

Nederhand, J., Steen, M. V. D., \& Twist, M. V. (2019). Boundary-spanning strategies for aligning institutional logics: A typology. Local Government Studies, 45(2), 219-240.

Rawluk, A., Ford, R. M., Little, L., Draper, S., \& Williams, K. J. H. (2020). Applying social research: How research knowledge is shaped and changed for use in a bushfire management organisation. Environmental Science \& Policy, 106, 201-209.

Reed, M. S., Graves, A., Dandy, N., Posthumus, H., Hubacek, K., Morris, J., . . . Stringer, L. C. (2009). Who's in and why? A typology of stakeholder analysis methods for natural resource management. Journal of Environmental Management, 90(5), 1933-1949.

Sachs, J., Schmidt-Traub, G., Kroll, C., Lafortune, G., Fuller, G., \& Woelm, F. (2020). The Sustainable Development Goals and COVID-19: Sustainable development report 2020. Cambridge: Cambridge University Press.

SAPEA. (2019). Making sense of science: For policy under conditions of complexity and uncertainty. Brussels: SAPEA.

Sarkki, S., Tinch, R., Niemelä, J., Heink, U., Waylen, K., Timaeus, J., . . .van den Hove, S. (2015). Adding 'iterativity' to the credibility, relevance, legitimacy: A novel scheme to highlight dynamic aspects of sciencepolicy interfaces. Environmental Science \& Policy, 54, 505-512.

Scharpf, F. W. (1997). Games real actors play: Actorcentered institutionalism in policy research. Boulder, CO: Westview Press.

Schmalzbauer, B., \& Visbeck, M. (2017). The Sustainable Development Goals: Conceptual approaches for science and research projects. Paper presented the 19th EGU General Assembly, Vienna, Austria.

Schneider, F., Kläy, A., Zimmermann, A. B., Buser, T., Ingalls, M., \& Messerli, P. (2019). How can science support the 2030 Agenda for Sustainable Development? Four tasks to tackle the normative dimension of sustainability. Sustainability Science, 14(6), 1593-1604.

SDSN Afghanistan. (2020). SDSN Afghanistan. United 
Nations SDSN. Retrieved from https://www.unsdsn. org/afghanistan

SDSN Belgium. (2020). SDSN Belgium. United Nations SDSN. Retrieved from https://www.unsdsn.org/ belgium

SDSN Bolivia. (2020). SDSN Bolivia. SDSN Bolivia. Retrieved from https://www.sdsnbolivia.org/en

SDSN Canada. (2020). Sustainable development solutions network (SDSN) Canada. University of Waterloo. Retrieved from https://uwaterloo.ca/sustainabledevelopment-solutions-network-canada/about

SDSN Greece. (2020). United Nations SDSN senior working group for the energy transition: Six transformations to achieve the SDGs and support for the European Green Deal. SDSN Greece. Retrieved from http://www.unsdsn.gr/pathways-to-achieve-theeuropean-green-deal-senior

SDSN Indonesia. (2020). SDSN Indonesia. United Nations SDSN. Retrieved from https://www.unsdsn.org/ indonesia

SDSN Malaysia. (2020). SDSN Malaysia. United Nations SDSN. Retrieved from https://www.unsdsn.org/ malaysia

SDSN Russia. (2020). SDSN Russia. United Nations SDSN. Retrieved from https://www.unsdsn.org/russia

SDSN Switzerland. (2020). SDSN Switzerland. SDSN Switzerland. Retrieved from https://www.sdsn.ch/ about

Sending, J. (2019). Knowledge networks, scientific communities, and evidence-informed policy. In D. Stone \& K. Moloney (Eds.), The Oxford handbook of global policy and transnational administration (pp. 383-400). Oxford: Oxford University Press.

Siebenhüner, B. (2008). Learning in international organizations in global environmental governance. Global Environmental Politics, 8(4), 92-116.

Sjöstedt, V., \& Kleinschmit, D. (2015). Frames in environmental policy integration: Are Swedish sectors on track? Environment and Planning C: Government and Policy, 23, 207-226.

The World Bank. (2020). Worldwide governance indicators. The World Bank. Retrieved from https:// databank.worldbank.org/source/worldwidegovernance-indicators

Turnhout, E. (2018). The politics of environmental knowledge. Conservation and Society, 16(3), 363-371.

United Nations. (2019). Global sustainable development report 2019: The future is now: Science for achieving sustainable development. New York, NY: United Nations. https://doi.org/10.18356/5d04ad97-en

United Nations. (2020). The sustainable development goals report 2020. New York, NY: United Nations. Retrieved from https://unstats.un.org/sdgs/report/ 2020/The-Sustainable-Development-Goals-Report2020.pdf

United Nations SDSN. (2020). SDSN networks. United Nations SDSN. Retrieved from https://www.unsdsn. org/networks-overview

Van der Hel, S., \& Biermann, F. (2017). The authority of science in sustainability governance: A structured comparison of six science institutions engaged with the Sustainable Development Goals. Environmental Science \& Policy, 77, 211-220.

Weber, E. P., \& Khademian, A. M. (2008). Wicked problems, knowledge challenges, and collaborative capacity builders in network settings. Public Administration Review, 68(2), 334-349.

Zeigermann, U. (2020). Science-based actor networks and knowledge integration for the Sustainable Development Goals. Manuscript submitted for publication.

Zeigermann, U., \& Böcher, M. (2019). Challenges for bridging the gap between knowledge and governance in sustainability policy: The case of OECD 'focal points' for policy coherence for development. Forest Policy and Economics. https://doi.org/10.1016/ j.forpol.2019.102005

\section{About the Author}

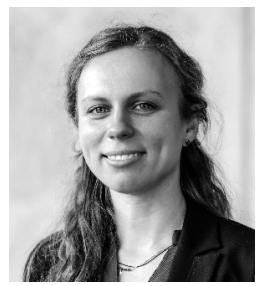

Ulrike Zeigermann is a Postdoctoral Researcher at the Department for Political Science and Sustainable Development at the University of Magdeburg. She is also as an Associated Fellow at the Marc Bloch Centre in Berlin, where she co-directs the 'Energy Transitions and Climate Governance' research group. Ulrike holds a PhD in Political Science from Münster University. Her research interests include the 2030 Agenda, environmental governance, knowledge circulation processes, and policy analysis more broadly. 